ORIGINAL ARTICLE

\title{
Pubertal stage and hypoglycaemia counterregulation in type 1 diabetes
}

\author{
L A Ross, R E Warren, C J H Kelnar, B M Frier
}

Arch Dis Child 2005;90:190-194. doi: 10.1136/adc.2004.052035

See end of article for authors' affiliations

.....................

Correspondence to:

Professor B M Frier,

Department of Diabetes,

Royal Infirmary of

Edinburgh, 51 Little France

Crescent, Edinburgh EH16

4SA, Scotland, UK; brian.

frier@luht.scot.nhs.uk

Accepted 21 May 2004

\begin{abstract}
Aims: To compare physiological and autonomic responses to acute hypoglycaemia in diabetic children in pre-, mid-, and post-pubertal stages of development.

Methods: Twenty seven children (8 pre-pubertal, 7 mid-pubertal, 12 post-pubertal) with type 1 diabetes were studied. Hypoglycaemia was induced by insulin infusion until an autonomic reaction (R) was identified. Counterregulatory hormone levels were measured at baseline, $R, R+15$, and $R+30$ minutes. Haemodynamic changes and sweat production were measured.

Results: The mean blood glucose level at $R$ was lower in pre-pubertal than mid-pubertal children $(2.0$ v 2.5 $\mathrm{mmol} / \mathrm{l})$, and was positively correlated with $\mathrm{HbA}_{l_{\mathrm{c}}}$. Glucagon and noradrenaline responses to hypoglycaemia were minimal in all children. A brisk increase in pancreatic polypeptide (PP) concentration only occurred in post-pubertal children. Only two children showed a sweating response to hypoglycaemia. Conclusions: The blood glucose level at which sympatho-adrenal responses to hypoglycaemia were activated was associated with glycaemic control, and varied with pubertal stage. As in adults, the glucagon response to hypoglycaemia was deficient within a few years of developing diabetes. However, sweating and secretion of PP in response to hypoglycaemia did not occur until after puberty, indicating some qualitative differences from adults.
\end{abstract}

$H$ ypoglycaemia is a common side effect of insulin therapy. Diabetic individuals are partially protected by various physiological mechanisms that protect against hypoglycaemia. In non-diabetic individuals, counterregulatory hormones are secreted when blood glucose declines to around $3.8 \mathrm{mmol} / \mathrm{l}^{1-3}$ These include catecholamines, glucagon, growth hormone, and cortisol. At around $3.0 \mathrm{mmol} / \mathrm{l} \mathrm{a}$ symptomatic response is generated. ${ }^{13}$ However, in diabetic adults, the magnitude and blood glucose thresholds for these responses may be altered as a consequence of prior glycaemic exposure. $^{45}$

Differences in the counterregulatory responses to hypoglycaemia in children compared to adults have been observed. Amiel et al and Jones et al reported higher peak catecholamine concentrations in children than in adults, both with and without diabetes. ${ }^{67}$ Although other groups have not replicated these results, ${ }^{8-10}$ no direct comparisons were made between adults and children in those studies. Further differences between children and adults involve the glycaemic threshold for generation of hypoglycaemic symptoms, and the nature of these symptoms. Jones et al reported that the blood glucose level needed to induce hypoglycaemic symptoms was lower in non-diabetic adults than nondiabetic children. ${ }^{7}$ In adults, discrete groups of autonomic and neuroglycopenic symptoms have been identified from multifactorial analysis of the symptoms of hypoglycaemia. ${ }^{11}{ }^{12}$ However, autonomic symptoms cosegregated with neuroglycopenic symptoms in diabetic children, ${ }^{13}{ }^{14}$ suggesting that children are unable to differentiate these groups.

It is possible that children are sensitive to lesser degrees of hypoglycaemia than adults; this would explain their higher blood glucose level at the onset of symptoms, and the greater hormonal response to a similar hypoglycaemic stimulus. If so, there may be a stage of development at which the responses to hypoglycaemia change from those typical of children to those typical of adults. It is known that insulin resistance increases during puberty, ${ }^{15-17}$ which may contribute to the deterioration in glycaemic control that often occurs during adolescence. It is possible that the responses to hypoglycae- mia also change during puberty. The present study was designed to compare the responses to hypoglycaemia in children in pre-pubertal, mid-pubertal, and post-pubertal stages of development.

The fixed rate insulin infusion technique simulates the development of hypoglycaemia in everyday life, and permits identification of the threshold for autonomic responses to hypoglycaemia. The autonomic response to hypoglycaemia can be identified by a sudden rise in heart rate and changes in blood pressure, which are induced by sympatho-adrenal activation. This method has been used previously to examine the effects of hypoglycaemia on autonomic activation in diabetic adults, ${ }^{18}{ }^{19}$ and was employed in the present study to identify the blood glucose threshold for sympatho-adrenal activation in children.

\section{SUBJECTS AND METHODS Subjects}

The study protocol was approved by the local ethics committee, and informed consent was obtained from all children and their parents.

Children attending diabetes clinics at the Royal Hospital for Sick Children, Edinburgh, and the Royal Infirmary of Edinburgh were eligible if they met the following criteria: aged 9-17 years; insulin treated type 1 diabetes mellitus (TIDM) for at least two years; and glycated haemoglobin $\left(\mathrm{HbA}_{1 \mathrm{c}}\right.$ ) between $6.5 \%$ and $11 \%$ (contemporary non-diabetic adult reference range $4.0-5.8 \%$ ). Children with a history of recurrent severe hypoglycaemia, or hypoglycaemia induced convulsion, neurological deficit, or other hypoglycaemic reaction of concern to the researcher were excluded. Children with a history of known nocturnal hypoglycaemia within the previous three months were excluded. Twenty

Abbreviations: ANOVA, analysis of variance; $\mathrm{BMI}$, body mass index; $\mathrm{CV}$, coefficient of variation; $\mathrm{FSH}$, follicle stimulating hormone; $\mathrm{HbA}_{\mathrm{lc}}$, glycated haemoglobin; IRMA, immunoradiometric assay; $\mathrm{LH}$, luteinising hormone; PP, pancreatic polypeptide; TIDM, type 1 diabetes mellitus 
Table 1 Clinical and demographic characteristics of subjects

\begin{tabular}{llll}
\hline & $\begin{array}{l}\text { Pre-pubertal } \\
\mathbf{n = 8}\end{array}$ & $\begin{array}{l}\text { Mid-pubertal } \\
\mathbf{n = 7}\end{array}$ & $\begin{array}{l}\text { Post-pubertal } \\
\mathbf{n = 1 2}\end{array}$ \\
\hline Male: female & $4: 4$ & $3: 4$ & $5: 7$ \\
Age (years) & $10.4(9.0-13.6)$ & $13.4(10.5-14.8)$ & $14.3(12.9-16.6)$ \\
Diabetes duration (years) & $4.5(2.0-7.0)$ & $5.5(2.0-11.0)$ & $5.3(3.0-12.0)$ \\
Weight $(\mathrm{kg})$ & $41(27-52)$ & $47(42-61)$ & $67(54-74)$ \\
$\mathrm{BMl}\left(\mathrm{kg} / \mathrm{m}^{2}\right)$ & $18.9(17.2-22.6)$ & $19.7(16.2-22.1)$ & $23.4(19.6-29.9)$ \\
$\mathrm{HbA} \mathrm{fc}_{\mathrm{c}}(\%)$ & $8.3(6.2-10.0)$ & $8.5(5.6-10.3)$ & $8.7(6.0-10.0)$ \\
\hline Data are medians (ranges). & & \\
\hline
\end{tabular}

seven children were included; table 1 presents their demographic characteristics.

The pubertal status of each child was staged by breast or genital development according to Tanner's criteria. ${ }^{2021}$ Girls who were post-menarche and boys who had reached genitalia stage 5 were classified as post-pubertal. In other children, pubertal status was determined by measurements of FSH, LH, and testosterone or oestradiol, and measurement of uterine volume by ultrasound in girls. ${ }^{22}{ }^{23}$ Table 2 summarises staging criteria. There were no significant differences between groups with respect to duration of diabetes or $\mathrm{HbA}_{1 \mathrm{c}}$.

\section{Methods \\ Induction of hypoglycaemia}

Each child attended for a single study with a parent at 0800 hours after fasting overnight, having received no insulin since the previous evening. The study was postponed if the child had reported any evidence of hypoglycaemia during the preceding 24 hours, a blood glucose level below $7.0 \mathrm{mmol} / \mathrm{l}$ before bed, or an initial blood glucose below $4.5 \mathrm{mmol} / \mathrm{l}$ on the morning of the study. If the initial blood glucose was between 4.5 and $8.0 \mathrm{mmol} / \mathrm{l}$, this was deemed the baseline point for the study, and if it was greater than $8.0 \mathrm{mmol} / \mathrm{l}$, insulin was infused to achieve a baseline blood glucose below $8.0 \mathrm{mmol} / \mathrm{l}$.

Blood samples and physiological measurements were taken at baseline as detailed below. An insulin infusion (Actrapid, Novo Nordisk) was then commenced at $1.5 \mathrm{mU} / \mathrm{kg} / \mathrm{min}$, to lower blood glucose. Blood samples were drawn from a venous cannula in the non-dominant hand, which was placed in a heated blanket to arterialise venous blood, ${ }^{25}$ and whole blood glucose was measured every five minutes (Yellow Springs Instruments, Farnborough, UK). The acute autonomic reaction (R) was identified by a subjectively determined sudden increase in heart rate, with a minimum $20 \%$ increase from the baseline rate, and development of peri-oral pallor and increment in pulse pressure. Children frequently reported symptoms of hypoglycaemia at the same moment. Figure 1 illustrates the haemodynamic responses to hypoglycaemia. When $\mathrm{R}$ was identified, the insulin infusion was discontinued and euglycaemia was restored by glucose infusion.

\section{Physiological measurements}

Heart rate was measured every five minutes using an electrocardiograph. Blood pressure was measured every five minutes using an automated sphygmomanometer. Finger tremor was measured every 10 minutes using a Bruel \& Kjaer 4367 accelerometer as described previously. ${ }^{26}$ Sweat formation was measured using a Dew Point hygrometer (Michell Instruments Ltd, Cambridge, UK) as described previously. ${ }^{18} 19$

\section{Symptoms of hypoglycaemia}

Subjects scored symptoms derived from previous research ${ }^{11-14}$ every 10 minutes.

\section{Hormone assays}

Blood samples were drawn twice at baseline ( 15 minutes apart), R, R+15, and R+30 minutes. Cortisol, glucagon, and pancreatic polypeptide (PP) were measured by radioimmunoassay (inter-assay coefficients of variation (CV) 8\%, 12\%, and $10 \%$ respectively). Growth hormone was measured by IRMA (CV 9\%). Adrenaline and noradrenaline were measured by high performance liquid chromatography (CV 2.9\% and $1.6 \%$ respectively).

\section{Autonomic function testing}

Each child underwent tests of autonomic neural function on a separate day prior to the main study. These comprised heart rate variation to deep breathing, standing, and Valsalva manoeuvre, and blood pressure response to standing and sustained handgrip. Results were classified according to published adult norms. ${ }^{24}$

\section{Statistical methods}

Analyses were performed using SPSS version 11. One way analyses of variance (ANOVA) for all three pubertal groups were performed first; when significant, further betweengroup comparisons were performed with $t$ tests. For withinsubject comparisons, paired sample $t$ tests were used. Associations between continuous variables were evaluated with Pearson correlations. Statistical significance was accepted at $\mathrm{p}<0.05$ (two tailed).

Table 2 Summary of pubertal staging process

\begin{tabular}{|c|c|c|c|c|c|c|}
\hline & \multicolumn{2}{|l|}{ Pre-pubertal } & \multicolumn{2}{|l|}{ Mid-pubertal } & \multicolumn{2}{|l|}{ Post-pubertal } \\
\hline & $\begin{array}{l}\text { Male } \\
n=4\end{array}$ & $\begin{array}{l}\text { Female } \\
n=4\end{array}$ & $\begin{array}{l}\text { Male } \\
n=3\end{array}$ & $\begin{array}{l}\text { Female } \\
n=4\end{array}$ & $\begin{array}{l}\text { Male } \\
n=5\end{array}$ & $\begin{array}{l}\text { Female } \\
n=7\end{array}$ \\
\hline $\begin{array}{l}\text { Tanner stage } \\
\text { FSH (U/I) } \\
\text { LH (U/I) } \\
\text { Oestradiol (pmol/I) } \\
\text { Testosterone (nmol/l) } \\
\text { Pelvic ultrasound }\end{array}$ & $\begin{array}{l}\text { Genitalia stage } 1 \\
<2.3 \\
<1.0 \\
<0.8\end{array}$ & $\begin{array}{l}\text { Breast stage } 1 \\
<3.5 \\
<1.0 \\
<50 \\
\text { Pre-pubertal }\end{array}$ & $\begin{array}{l}\text { Genitalia stage } 2-4 \\
3.1-4.1 \\
1.0-1.5 \\
0.9-8.2\end{array}$ & $\begin{array}{l}\text { Breast stage } 2-4 \\
3.2-6.4 \\
2.8-5.4 \\
60-110 \\
\text { Mid-pubertal }\end{array}$ & Genitalia stage 5 & Post-menarche \\
\hline
\end{tabular}




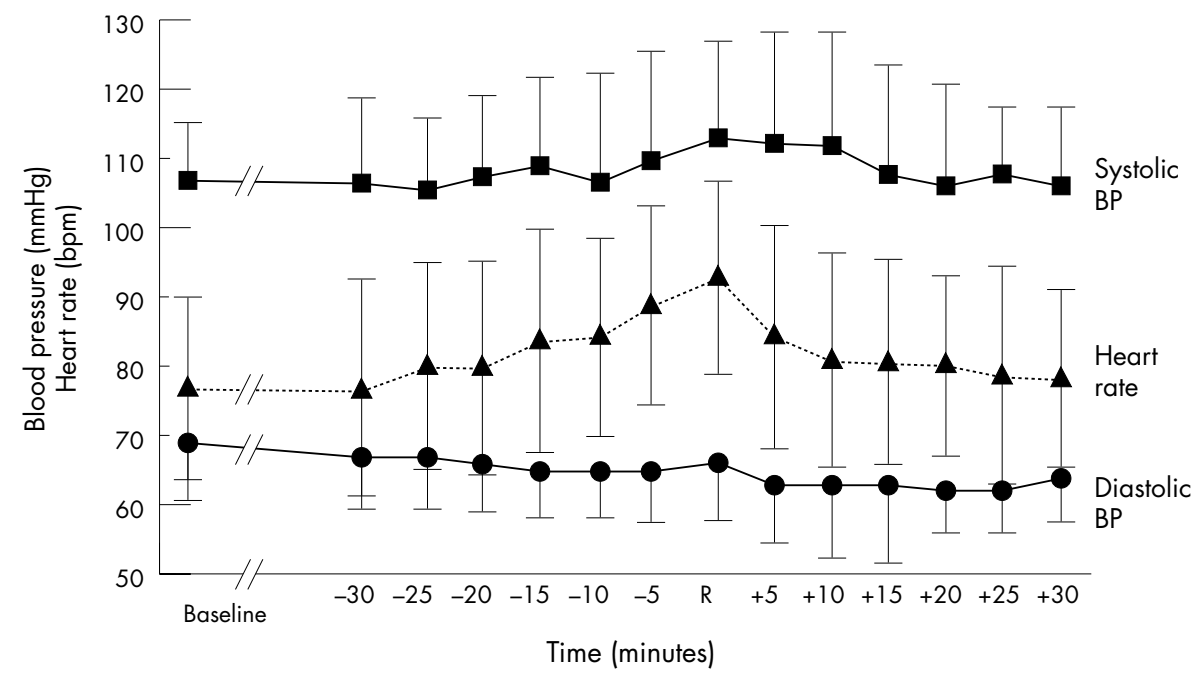

Figure 1 Changes in heart rate and blood pressure induced by hypoglycaemia.

\section{RESULTS}

Table 3 presents blood glucose and hormonal results.

\section{Blood glucose}

There were no significant between-group differences in baseline blood glucose concentration. The time taken to reach $\mathrm{R}$ ranged from 30 to 100 minutes, and was generally shorter in pre-pubertal children (mean 47 minutes) than mid- or post-pubertal children (66 and 65 minutes). The rate of fall of blood glucose ranged from 0.048 to $0.102 \mathrm{mmol} / \mathrm{l} /$ min, and was faster in pre-pubertal children (mean $0.90 \mathrm{mmol} / \mathrm{l} / \mathrm{min}$ ) than mid- and post-pubertal children ( 0.64 and $0.59 \mathrm{mmol} / \mathrm{l} / \mathrm{min})$. There were significant between-group differences in blood glucose at $\mathrm{R}(\mathrm{F}=3.645$, $\mathrm{p}=0.041)$. Post-hoc comparisons revealed a significant difference between the pre-pubertal and mid-pubertal groups only $(\mathrm{t}=3.418, \mathrm{p}=0.005)$.

A significant correlation was observed between $\mathrm{HbA}_{1 \mathrm{c}}$ and blood glucose concentration at $R(r=0.409, p=0.034)$ (fig 2 ). The blood glucose concentration at $\mathrm{R}$ was not significantly associated with age, duration of diabetes, or gender.

\section{Symptoms}

Total, autonomic and neuroglycopenic symptoms increased significantly in all groups, reaching a peak at R.

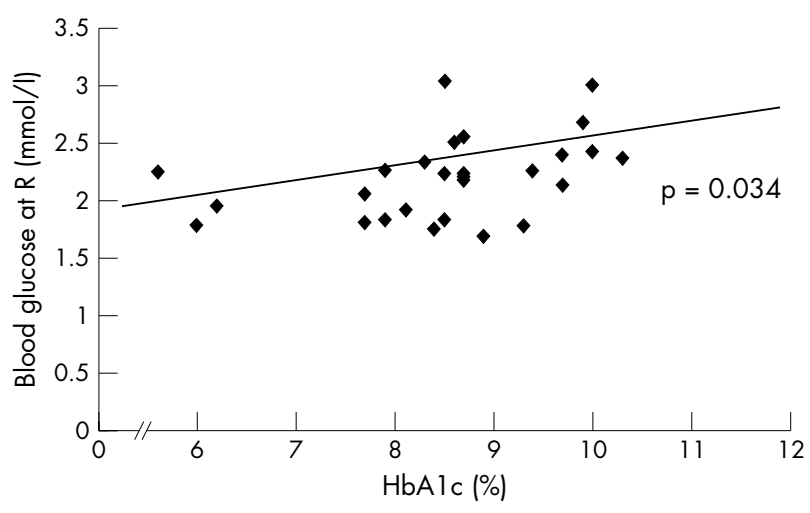

Figure 2 Relation of $\mathrm{HbA}_{1 \mathrm{c}}$ to blood glucose concentration at the onset of the autonomic reaction $(R)$.

Table 3 Biochemical measurements at baseline and at autonomic reaction (R) (and peak if after R)

\begin{tabular}{|c|c|c|c|c|c|}
\hline Measurement & Time & All & Pre-pubertal & Mid-pubertal & Post-pubertal \\
\hline Blood glucose $(\mathrm{mmol} / \mathrm{l})$ & $\begin{array}{l}\text { Baseline } \\
\mathrm{R}\end{array}$ & $\begin{array}{l}6.2(0.17) \\
2.2(0.07)\end{array}$ & $\begin{array}{l}6.1(0.21) \\
2.0(0.09)^{*}\end{array}$ & $\begin{array}{l}6.6(0.39) \\
2.5(0.10)\end{array}$ & $\begin{array}{l}6.0(0.26) \\
2.2(0.11)\end{array}$ \\
\hline Adrenaline (nmol/l) & $\begin{array}{l}\text { Baseline } \\
\mathrm{R}\end{array}$ & $\begin{array}{l}0.47(0.10) \\
2.14(0.24)\end{array}$ & $\begin{array}{l}0.84(0.18) \\
2.18(0.48)\end{array}$ & $\begin{array}{l}0.66(0.21) \\
1.65(0.26)\end{array}$ & $\begin{array}{l}0.12(0.04) \ddagger \\
2.39(0.49)\end{array}$ \\
\hline Noradrenaline (nmol/l) & $\begin{array}{l}\text { Baseline } \\
\mathrm{R}\end{array}$ & $\begin{array}{l}1.23(0.67) \\
1.24(0.62)\end{array}$ & $\begin{array}{l}1.31(0.27) \\
1.51(0.15)\end{array}$ & $\begin{array}{l}0.90(0.21) \\
0.74(0.23) \dagger\end{array}$ & $\begin{array}{l}1.45(0.21) \\
1.41(0.21)\end{array}$ \\
\hline Glucagon (ng/l) & $\begin{array}{l}\text { Baseline } \\
\mathrm{R}\end{array}$ & $\begin{array}{l}48.0(1.95) \\
51.7(2.28)\end{array}$ & $\begin{array}{l}50.0(4.2) \\
51.2(4.6)\end{array}$ & $\begin{array}{l}48.9(2.8) \\
49.3(3.4)\end{array}$ & $\begin{array}{l}46.0(2.7) \\
53.3(3.8)\end{array}$ \\
\hline Cortisol (nmol/l) & $\begin{array}{l}\text { Baseline } \\
R \\
R+30\end{array}$ & $\begin{array}{l}227(26) \\
310(25) \\
474(31)\end{array}$ & $\begin{array}{l}241(26) \\
244(13) \\
383(52)\end{array}$ & $\begin{array}{l}194(30) \\
334(52) \\
472(92)\end{array}$ & $\begin{array}{l}238(54) \\
339(46) \\
536(40)\end{array}$ \\
\hline Growth hormone (mU/I) & $\begin{array}{l}\text { Baseline } \\
R \\
R+15\end{array}$ & $\begin{array}{l}4.4(0.9) \\
28.0(5.7) \\
47.2(5.7)\end{array}$ & $\begin{array}{l}2.4(0.8) \\
8.3(2.8) \\
25.0(5.9)\end{array}$ & $\begin{array}{l}6.4(2.8) \\
33.8(12.1) \\
48.4(12.8)\end{array}$ & $\begin{array}{l}4.5(1.1) \\
36.1(9.0) \\
56.6(8.2)\end{array}$ \\
\hline Pancreatic polypeptide (ng/l) & $\begin{array}{l}\text { Baseline } \\
\mathrm{R}\end{array}$ & $\begin{array}{l}63(8) \\
466(100)\end{array}$ & $\begin{array}{l}76(21) \\
63(19)\end{array}$ & $\begin{array}{l}49(11) \\
367(202)\end{array}$ & $\begin{array}{l}62(8) \\
793(143) \S\end{array}$ \\
\hline
\end{tabular}

Results are expressed as mean (SE) unless stated otherwise. Baseline results are the means of two baseline measurements.

Significance levels are for between-group comparisons at single time points.

${ }^{*} p=0.005$ versus mid-pubertal group.

$\mathrm{tp}<0.05$ versus pre-pubertal group.

$\neq p=0.003$ versus mid-pubertal group, $p<0.001$ versus pre-pubertal group

$\S p=0.001$ versus pre-pubertal group. 


\section{Adrenaline}

Adrenaline concentrations rose significantly during hypoglycaemia within each group. No significant differences between groups were found at $\mathrm{R}$.

\section{Noradrenaline}

Concentrations at $\mathrm{R}$ differed $(\mathrm{F}=4.247, \mathrm{p}=0.029)$, and were lower in mid-pubertal than pre-pubertal children $(\mathrm{t}=2.866$, $\mathrm{p}=0.013)$. However, no significant differences at baseline, and no significant increments between baseline and $\mathrm{R}$, were observed.

\section{Glucagon}

In all children combined, glucagon concentrations rose minimally $(t=2.056, p=0.050)$. There were no significant differences between groups.

\section{Cortisol and growth hormone}

Significant increases were seen for both hormones, reaching peaks after $\mathrm{R}$ (table 3 ). There were no significant differences between groups.

\section{Pancreatic polypeptide}

Baseline PP concentrations did not differ significantly between groups. A significant rise was seen in the postpubertal group only $(\mathrm{t}=-5.517, \mathrm{p}<0.001)$ (fig 3 ). In the mid-pubertal group, there were brisk PP responses in two children and negligible responses in the remainder.

\section{Sweating}

An increase in sweat formation was observed in only two children, both post-pubertal. In other children, no increase in sweating was detected by hygrometry or inspection.

\section{Tremor}

Tremor increased during hypoglycaemia in all groups.

\section{Autonomic function tests}

Most children were unable to sustain a handgrip, and this test was discounted. For the remaining four tests, 21 children had normal results. Three pre-pubertal, one mid-pubertal, and two post-pubertal children had one abnormal result. Definite autonomic neuropathy is associated with two or more abnormal results, ${ }^{24}$ and so all children were classified as having no evidence of significant neuropathy. Discarding the handgrip test is unlikely to have led to misclassification, as abnormal results on this test are associated with advanced

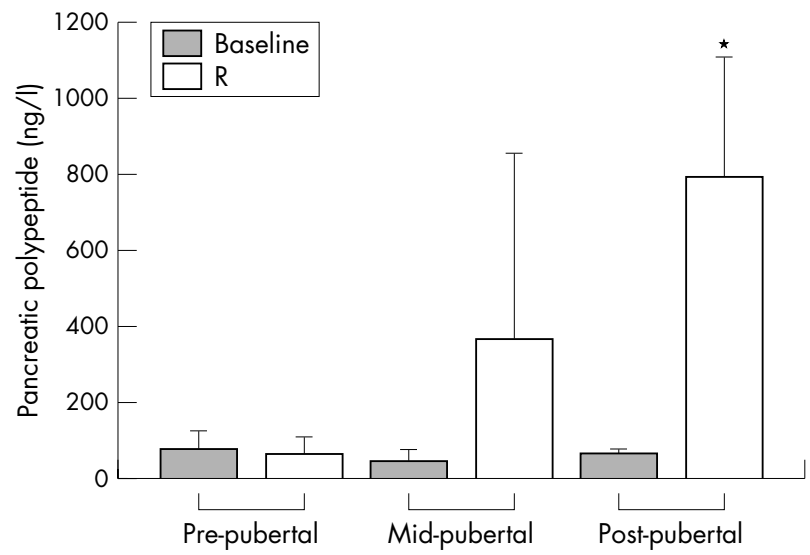

Figure 3 Pancreatic polypeptide levels in each pubertal group at baseline and at the onset of the autonomic reaction (R). ${ }^{*} p<0.001$ for comparisons with baseline level in post-pubertal group, and level at $R$ in pre-pubertal group. autonomic neuropathy, ${ }^{24}$ and no child had more than one other abnormal result.

\section{DISCUSSION}

Children have different responses to hypoglycaemia from adults, both in terms of symptoms ${ }^{13}{ }^{14}$ and catecholamine secretion. ${ }^{67}$ These differences may be related to the profound physical changes of puberty. In the present study, the blood glucose concentrations at the onset of the hypoglycaemic autonomic reaction were lower in pre-pubertal than midpubertal children (2.0 versus $2.5 \mathrm{mmol} / \mathrm{l})$. The glycaemic threshold in the post-pubertal group did not differ significantly from either. The difference in glycaemic thresholds suggests that sensitivity to hypoglycaemia is altered during puberty. However, as no significant differences were observed between children pre- and post-puberty, such changes may not be permanent.

The blood glucose level at which the autonomic response was triggered was positively correlated with $\mathrm{HbA}_{\mathrm{lc}}$. The thresholds for symptoms and counterregulation also vary with glycaemic control in adults, presumably due to adaptation to prevailing blood glucose concentrations and recurrent hypoglycaemia. ${ }^{27-29}$ The glucagon response was minimal and correlated with duration of diabetes, which is also consistent with previous studies. ${ }^{6} 103031$

No major differences in the catecholamine responses were identified. There was no significant noradrenaline increment in any group, and the apparently lower peak levels in the mid-pubertal group probably reflect a type 1 statistical error. The absence of a noradrenaline response was unexpected; although there are a few similar reports, ${ }^{95}$ the majority of previous studies in children ${ }^{6233}$ and adults ${ }^{1832} 34$ have reported brisk noradrenaline rises.

The pancreatic polypeptide response to hypoglycaemia was very different across puberty. In the pre-pubertal group, no increase occurred, whereas there was a brisk rise in the postpubertal group. In the mid-pubertal group there was a small, statistically insignificant increase, and this group appears to have been heterogeneous. We are only aware of one other study in which PP was measured in children, and in that study no rise was seen during spontaneous nocturnal hypoglycaemia. ${ }^{36}$ The PP response to hypoglycaemia is well established in adults as a marker of autonomic activation, and the response is attenuated in autonomic neuropathy. ${ }^{37}$ None of the children in the present study appeared to have significant autonomic neuropathy based on cardiovascular autonomic function tests, and thus the PP results appear to represent a qualitative change during puberty. It is possible that this represents maturation of the autonomic nervous system. It is conceivable that immaturity of the autonomic nervous system also explains the absence of a rise in serum noradrenaline, which derives in part from adrenergic neurones as well as the adrenal medulla. ${ }^{38}$

In all but two children, no sweating was observed despite overt, symptomatic hypoglycaemia. Previously, diabetic adults generated a sweating response within 30 seconds of the autonomic reaction. ${ }^{18} 19$ Thus, there also appears to be a qualitative difference between children and adults in this respect, supported by the fact that both children who did sweat were post-pubertal. This was surprising, as children with diabetes and their parents have previously identified sweating as a typical symptom or sign of hypoglycaemia. ${ }^{13} 14$ It would be valuable to measure sweat production in children in future studies to corroborate these findings. Hypoglycaemia in small children is common but difficult to identify, ${ }^{39}$ and the absence of a sign previously considered typical would be of considerable relevance to parents.

There are some limitations to the study. The fall of blood glucose could not be precisely controlled using the insulin 
infusion technique. In future studies, it would be of interest to determine the thresholds for, and magnitudes of, the symptomatic and hormonal responses to hypoglycaemia using the glucose clamp technique. This technique was not used in the present study in order to limit the duration of the experiment for our young subjects. The techniques differ in that the clamp technique permits measurement of responses at specified blood glucose levels, but does not allow identification of the autonomic response. An additional limitation is that children were not admitted overnight for intravenous insulin to prevent nocturnal hypoglycaemia. Although precautions were taken to exclude children with obviously increased risk of nocturnal hypoglycaemia, asymptomatic nocturnal hypoglycaemia is known to be frequent in children, ${ }^{36}$ and studies in adults indicate that this could affect the hormonal and symptomatic responses to experimental hypoglycaemia the next day. ${ }^{40}{ }^{41}$

In summary, this study has indicated that some responses to acute hypoglycaemia alter as diabetic children progress through puberty. Mid-pubertal children appeared to be more sensitive to hypoglycaemia than other children, although there was no permanent shift in the glycaemic threshold for the autonomic reaction. The pancreatic polypeptide response was absent in pre-pubertal children, but appeared to be fully developed after puberty. In contrast with diabetic adults, most children in the present study did not generate a sweating response. However, puberty was not associated with any modification of the counterregulatory hormonal response.

\section{ACKNOWLEDGEMENTS}

We wish to thank research nurses L Smith, L Gaughan, and C MacFarlane of the Royal Hospital for Sick Children, Edinburgh, for their assistance with the study, and Professor I Deary of the Department of Psychology, University of Edinburgh, for assistance with the study design. We thank Dr R Stephen of the Royal Hospital for Sick Children, Edinburgh, Dr J Ardill of the Wellcome Research Laboratories, Queens University, Belfast, and Dr C Gray of Glasgow Royal Infirmary, for providing the hormone assays.

\section{Authors' affiliations}

L A Ross, C J H Kelnar, Section of Child Life and Health, Department of Reproductive and Developmental Sciences, University of Edinburgh, Scotland, UK

R E Warren, B M Frier, Department of Diabetes, Royal Infirmary of Edinburgh, Scotland, UK

Competing interests: LAR was supported by independent funding from Novo Nordisk Pharmaceuticals Ltd. REW was supported by independent funding from Eli Lilly \& Co Ltd.

\section{REFERENCES}

1 Schwartz NS, Clutter WE, Shah SD, et al. Glycemic thresholds for activation of glucose counter-regulatory systems are higher than the threshold for symptoms. J Clin Invest 1987;79:777-81.

2 Cryer PE. Glucose counterregulation: the prevention and correction of hypoglycemia in humans. Am J Physiol 1993;264:E1 49-55.

3 Mitrakou A, Ryan C, Veneman T, et al. Hierarchy of glycemic thresholds for counterregulatory hormonal secretion, symptoms, and cerebral dysfunction. Am J Physiol 1991;260:E67-74.

4 Gerich JE, Bolli GB. Counterregulatory failure. In: Frier BM, Fisher BM, eds. Hypoglycaemia in diabetes. Clinical and physiological aspects. London: Edward Arnold, 1993:253-67.

5 Frier BM, Fisher BM. Impaired hypoglycaemia awareness. In: Frier BM, Fisher BM, eds. Hypoglycaemia in clinical diabetes. Chichester, UK: John Wiley \& Sons Ltd, 1999:111-46.

6 Amiel SA, Simonson DC, Sherwin RS, et al. Exaggerated epinephrine responses to hypoglycemia in normal and insulin-dependent diabetic children. J Pediatr 1987;1 10:832-7.

7 Jones TW, Boulware SD, Kraemer DT, et al. Independent effects of youth and poor diabetes control on responses to hypoglycemia in children. Diabetes $1991 ; 40: 358-63$.

8 Hoffman RP, Singer-Granick C, Drash AL, et al. Plasma catecholamine responses to hypoglycemia in children and adolescents with IDDM. Diabetes Care 1991;14:81-8.
9 Biørgaas M, Vik T, Sand T, et al. Counterregulatory hormone and symptom responses to hypoglycaemia in diabetic children. Diabet Med 1997; 14:433-41.

10 Brambilla P, Bougneres PF, Santiago JV, et al. Glucose counterregulation in pre-school-age diabetic children with recurrent hypoglycemia during conventional treatment. Diabetes 1987;36:300-4.

11 Hepburn DA, Deary IJ, Frier BM. Classification of symptoms of hypoglycaemia in insulin-treated diabetic patients using factor analysis: relationship to hypoglycaemia unawareness. Diabet Med 1992;9:70-5.

12 Deary IJ, Hepburn DA, MacLeod KM, et al. Partitioning the symptoms of hypoglycaemia using multi-sample confirmatory factor analysis. Diabetologia 1993;36:771-7.

13 McCrimmon RJ, Gold AE, Deary IJ, et al. Symptoms of hypoglycemia in children with IDDM. Diabetes Care 1995; 18:858-61.

14 Ross LA, McCrimmon RJ, Frier BM, et al. Hypoglycaemic symptoms reported by children with type 1 diabetes mellitus and by their parents. Diabet Med 1998; 15:836-43.

15 Amiel SA, Sherwin RS, Simonson DC, et al. Impaired insulin action in puberty: a contributor to poor diabetic control during adolescence. N Engl J Med 1986;315:215-19.

16 Bloch CA, Clemons $P$, Sperling M. Puberty decreases insulin sensitivity. J Pediatr 1987;110:481-7.

17 Smith CP, Archibald HR, Thomas JM, et al. Basal and stimulated insulin levels rise with advancing puberty. Clin Endocrinol 1988;28:7-14.

18 Hepburn DA, Patrick AW, Brash HM, et al. Hypoglycaemia unawareness in type 1 diabetes: a lower plasma glucose is required to stimulate sympathoadrenal activation. Diabet Med 1991;8:934-45.

19 Hepburn DA, MacLeod KM, Frier BM. Physiological, symptomatic and hormonal responses to acute hypoglycaemia in type 1 diabetic patients with autonomic neuropathy. Diabet Med 1993;10:940-9.

20 Marshall WA, Tanner JM. Variations in the pattern of pubertal changes in girls. Arch Dis Child 1969;44:291-303.

21 Marshall WA, Tanner JM. Variations in the pattern of pubertal changes in boys. Arch Dis Child 1970;45:13-23.

22 Sample WF, Lippe BM, Gyepes MT. Gray-scale ultrasonography of the normal female pelvis. Radiology 1977; 125:477-83.

23 Orsini LF, Salardi S, Pilu G, et al. Pelvic organs in premenarcheal girls: realtime ultrasonography. Radiology 1984;153:113-16.

24 Ewing DJ, Martyn CN, Young RJ, et al. The value of cardiovascular autonomic function tests: 10 years experience in diabetes. Diabetes Care 1985;8:491-8.

25 McGuire EAH, Helderman JH, Tobin JD, et al. Effect of arterial vs venous sampling on analysis of glucose kinetics in man. J Appl Physiol 1976;41:565-73

26 Birmingham AT, Wharrad HJ, Williams EJ, et al. Accelerometric measurements of finger tremor: analysis of the analogue signal. J Physiol (Lond) 1985;361:12P.

27 Clarke WL, Gonder-Frederick LA, Richards FE, et al. Multifactorial origin of hypoglycemic symptom awareness in IDDM. Diabetes 1991;40:680-5.

28 Amiel SA, Sherwin RS, Simonson DC, et al. Effect of intensive insulin therapy on glycemic thresholds for counter-regulatory hormone release. Diabetes 1988;37:901-7.

29 Kinsley BT, Widom B, Simonson DC. Differential regulation of counterregulatory hormone secretion and symptoms during hypoglycemia in IDDM. Effect of glycemic control. Diabetes Care 1995;18:17-26.

30 Singer-Granick C, Hoffman RP, Kerensky K, et al. Glucagon responses to hypoglycemia in children and adolescents with IDDM. Diabetes Care 1988; 11:643-9.

31 Gerich JE, Langlois $M$, Noacco $C$, et al. Lack of glucagon response to hypoglycemia in diabetes: evidence for an intrinsic pancreatic alpha cell defect. Science 1973;182:171-3.

32 De Feo P, Bolli G, De Cosmo S, et al. The adrenergic contribution to glucose counterregulation in type 1 diabetes mellitus: dependency on A-cell function and mediation through beta2-adrenergic receptors. Diabetes 1983;32:887-93.

33 Aman J, Wranne L. Hypoglycaemia in childhood diabetes. Acta Paediatr Scand 1988;77:542-7.

34 Bolli G, De Feo P, Compagnucci P, et al. Abnormal glucose counterregulation in insulin-dependent diabetes mellitus: interaction of anti-insulin antibodies and impaired glucagon and epinephrine secretion. Diabetes 1983:32:134-41.

35 White NH, Gingerich RL, Levandoski L, et al. Plasma pancreatic polypeptide response to insulin-induced hypoglycemia as a marker for defective glucose counterregulation in insulin-dependent diabetes mellitus. Diabetes 1985:34:870-5.

36 Matyka KA, Crowne EC, Havel PJ, et al. Counterregulation during spontaneous nocturnal hypoglycemia in pre-pubertal children with type 1 diabetes. Diabetes Care 1999;22:1144-50.

37 Hilsted J. Classical autonomic neuropathy and denervation. In: Frier BM, Fisher BM, eds. Hypoglycaemia in diabetes. Clinical and physiological aspects. London: Edward Arnold, 1993:268-74.

38 Fagius J, Niklasson F, Berne C. Sympathetic outflow in human muscle nerves increases during hypoglycemia. Diabetes 1986;35:1124-9.

39 Ryan C, Becker D. Hypoglycemia in children with type 1 diabetes mellitus: risk factors, cognitive function, and management. Endocrinol Metab Clin North Am 1999;28:883-900.

40 Heller S, Cryer P. Reduced neuroendocrine and symptomatic responses to subsequent hypoglycemia after one episode of hypoglycemia in nondiabetic humans. Diabetes 1991;40:223-6.

41 Veneman T, Mitrakou A, Mokan M, et al. Induction of hypoglycemia unawareness by asymptomatic nocturnal hypoglycemia. Diabetes 1993;42: 1233-7. 